بررسى اندازه قطر سنگ جين در اطراف تكيه گاه بِ در قوس \11 درجه رودخانه

مسعود ناصريان و عليرضا مسجدى

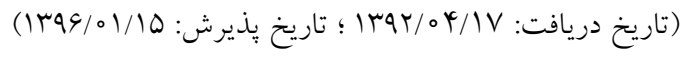

جكيده

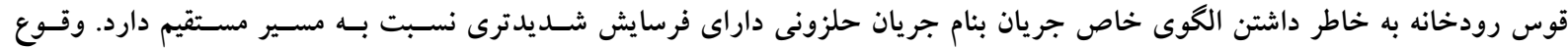

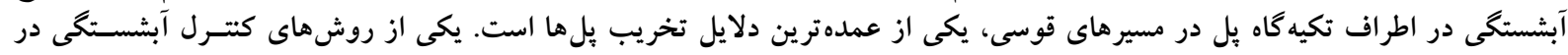

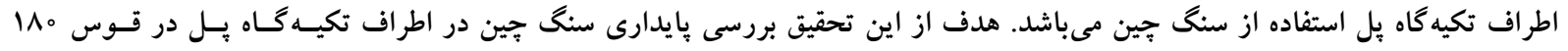

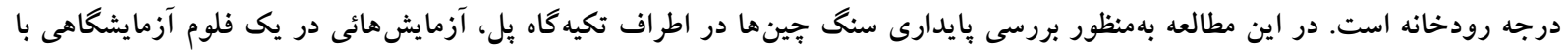

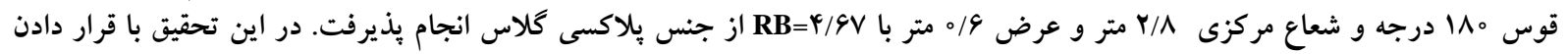

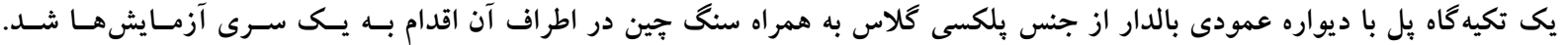

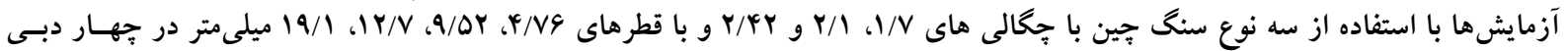

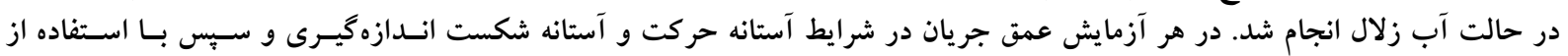

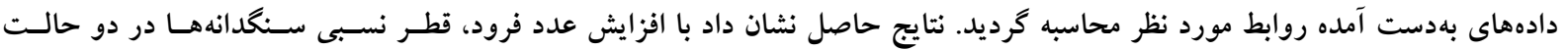

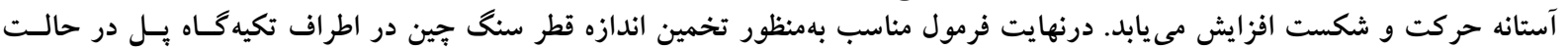

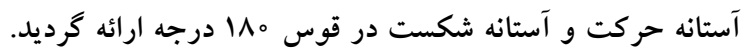

وازههاى كليدى: تكيه كاه بل، سنگ جين، قوس 011 درجه، جريان ثانويه 
حفره در محل تكيه كاه بِل شده و ممكن است موجب ريـزش و

خرابى تكيه كاه بل كردد.

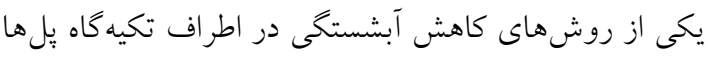

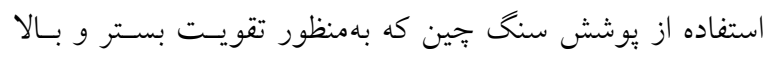
بردن مقاومت آن در برابر تنش برشى ناشسى از جريـان استفاده مى شوند.

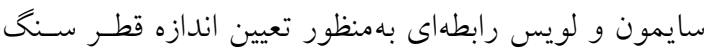

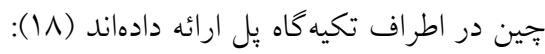

$\frac{\mathrm{D}_{\emptyset_{0}}}{\mathrm{y}}=\frac{\circ / 9 \mathrm{~V}}{\left(\mathrm{G}_{\mathrm{s}}-1\right)} \mathrm{Fr}^{\mathrm{r}}$

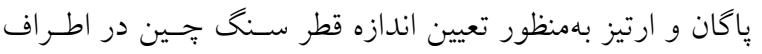

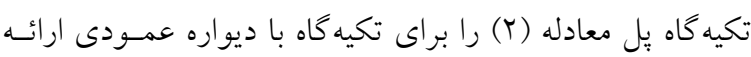

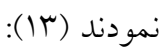

$\frac{D_{\omega^{\circ}}}{y}=\frac{1 / \circ \Delta}{\left(G_{S}-1\right)^{\circ / \Lambda 1}} \mathrm{Fr}^{1 / 9 r}$

سازمان حمل و نقل و ترافيك راه نيوزلند و استر اليا (؟) به نقـل

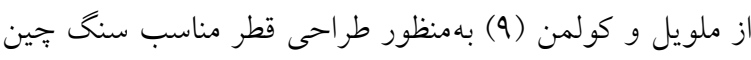
در محل تكيه گاه بل معادله (Y) را ارائه نمودند:

$\frac{D_{\omega_{0}}}{\mathrm{y}}=\frac{1 / 0{ }^{\varphi}}{\left(\mathrm{G}_{\mathrm{S}}-1\right)} \mathrm{Fr}^{r}$

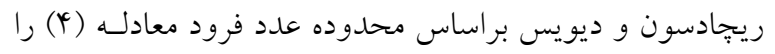

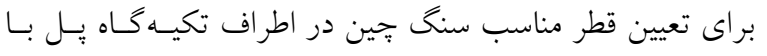
ديواره عمودى ارائه نمودند (19):

$\frac{D_{\omega_{0}}}{y}=\frac{1 / \circ r}{\left(G_{s}-1\right)} F^{r} \quad F r \leq \circ / 1$

زراتى و همكاران نيز عملكرد طوقههاى مستقل و ييوسته همراه

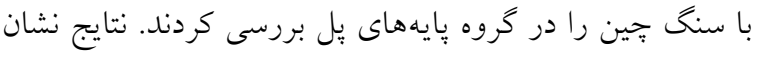

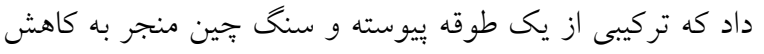

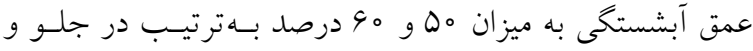

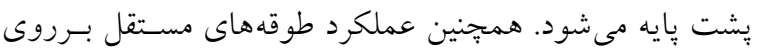

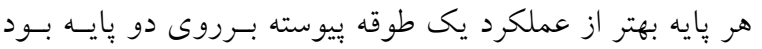

سوئى و همكاران مطالعه آزمايشخاهى روى اثر تكيه كاه يـلـ

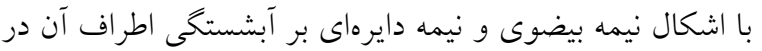

فرسايش در قوس رودخانه بهدليل وجود جريانهـاى حلزونى،

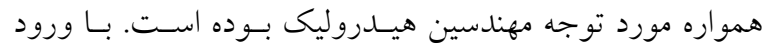
جريان به قوس نيروى كريز از مركز بر آن اثر مى كنــ كـهـ ايـنـ

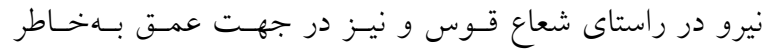

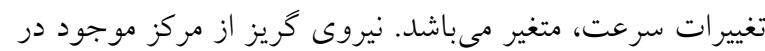

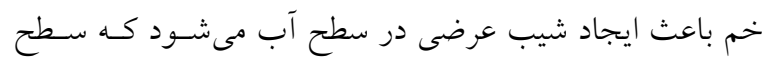

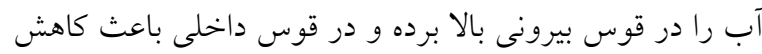

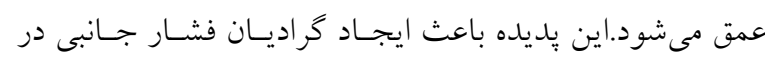

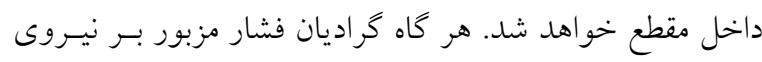

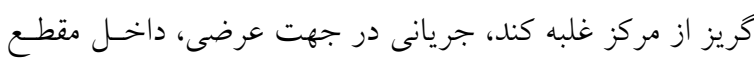

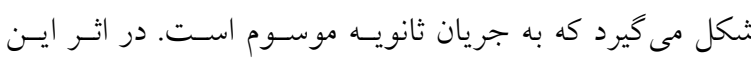

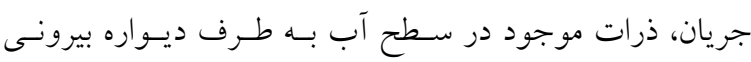

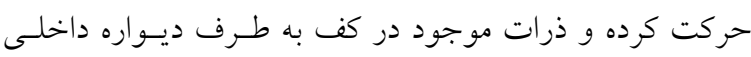
جابهجا مىشوند.

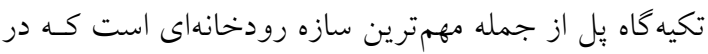

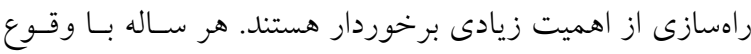

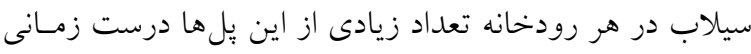

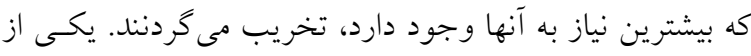

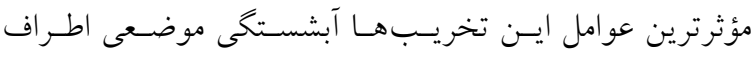

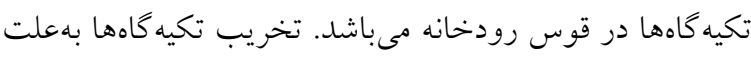
آبشستخى زيانهاى سنخين اقتصـادى و جـانبى بـهـ دنبـال دارد. براساس مطالعات سازمان بزرخراههاى ايـالات متحــــه در سـال

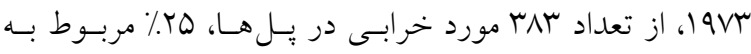

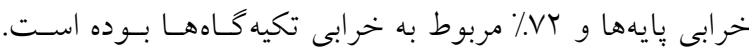

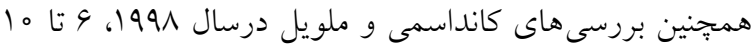

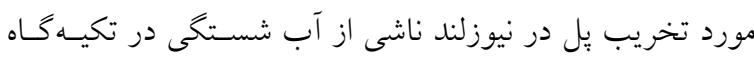
آنها بوده است (1) اخر تكيه كاهاى بهطور عمودى در مسير جريـان قـرار كرفتـهـ

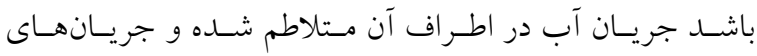

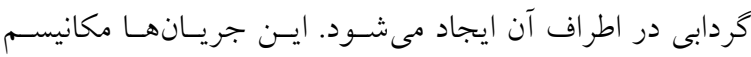

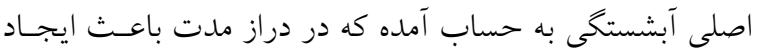


فلوم آزمايشگاهى با قوس 01/1 درجه از جنس بِاكسى گَلاس

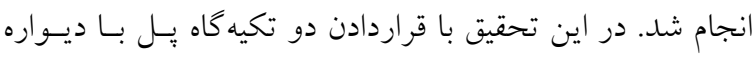

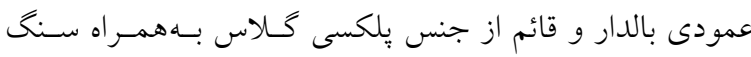

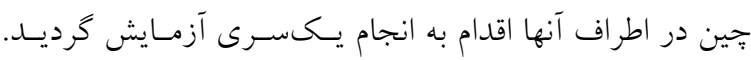

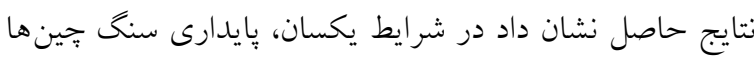

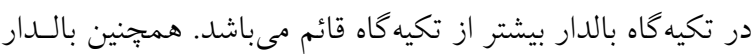

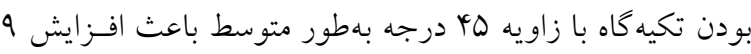

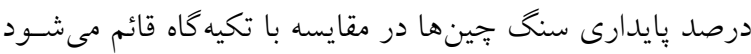

تكيه كاه بل سازههايى هستند كه از طرف سـاحل بـه داخـل

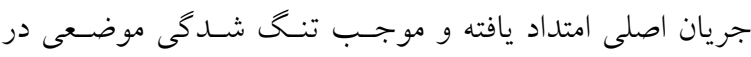

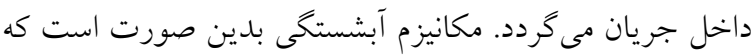

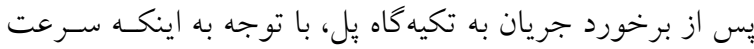

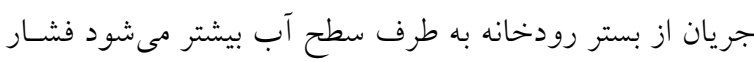
بيشترى نيز در ترازهاى بالاتر برروى بــالا دسـت تكيـهـــاه بــلـ

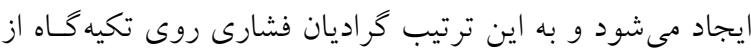

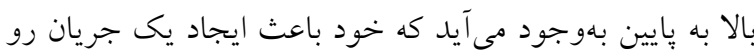

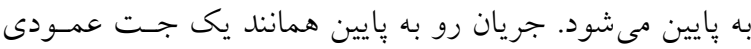
عمل كرده و يس از برخورد به بستر رودخانه ضمن حفر بستستر

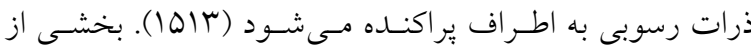

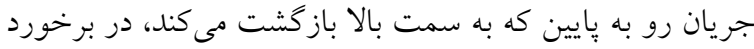
به جريان عمومى رودخانه، مجبور به حركت در جهـت جريـان

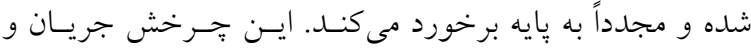

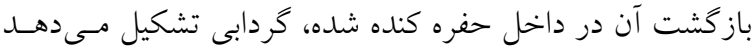

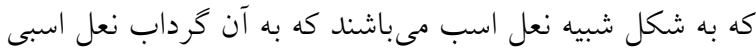

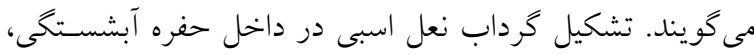

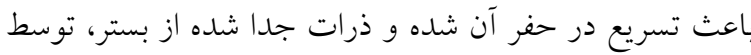
جريان اصلى رودخانه به بايين دست حمل مىشوند (V).

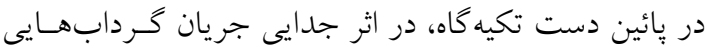

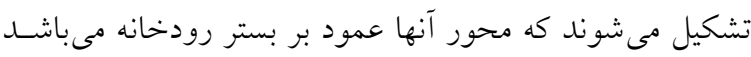

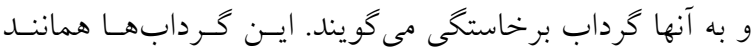

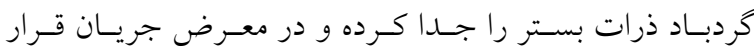

شرايط آب زلال و مصالح مختلف انجام دادند. نتايج آزمايشها

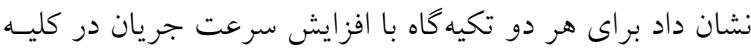

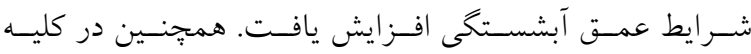

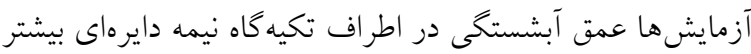

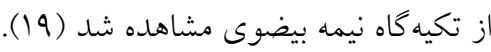

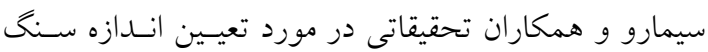
جين بهمنظور حفاظت از بايههاى يل در مقابل فرسـايش انجـام

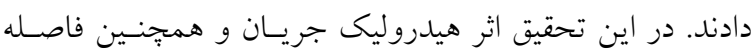

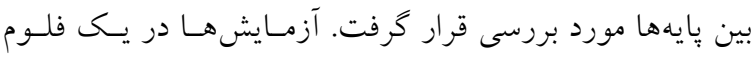

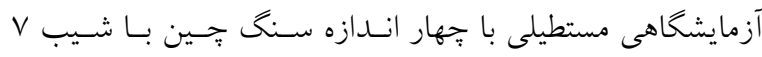

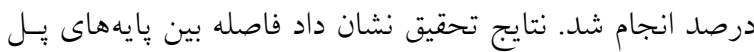
تأثير كمى برروى اندازه سنخ جين دارد (IV)

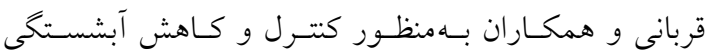

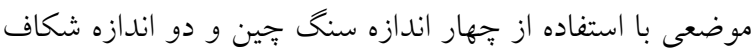

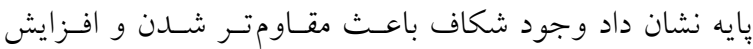
بايدارى بايدارى سنگ جين مى گردد (Y). كيخائى و همكاران در خصوص الكوى سنگ جين در محل

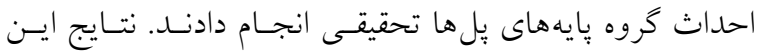
تحقيق نشان داد مساحت محدوده بوشش سنخ جين در گَروه

پِايهها براى هر بِيه نسبت به تكى بايه كاهش يافته است (r).

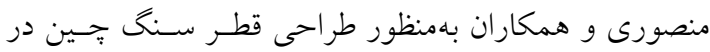

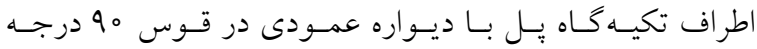

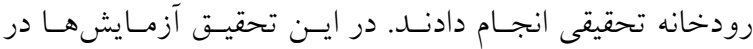
جֶ) علد فرود معادله (ه) را براى تعيين قطر مناسب سنگ جهين در

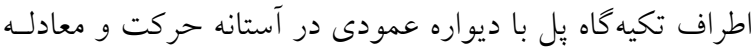
(צ) را براى آستانه شكست ارائه نمودند (†):

$\frac{\mathrm{D}_{\phi_{0}}}{\mathrm{y}_{\mathrm{t}}}=\frac{1 / 9 r}{\left(\mathrm{G}_{\mathrm{s}}-1\right)^{1 / / r}} \mathrm{Fr}^{\mathrm{r} / \Delta \psi}$

$\frac{D_{\phi_{0}}}{y_{t}}=\frac{\circ / \Delta q}{\left(G_{s}-1\right)^{1 / / v}} \mathrm{Fr}^{r / r r}$

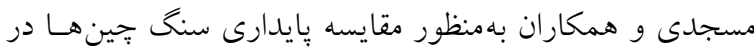

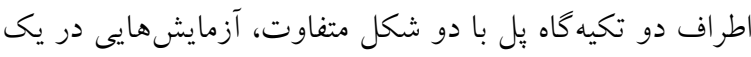




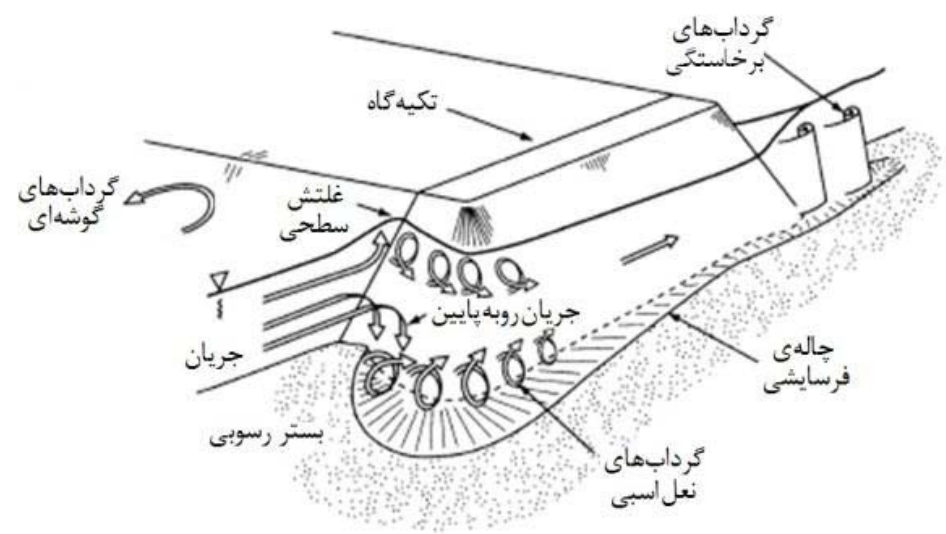

شكل ا. الكوى جريان و حفره آبشستخى موضعى اطراف يك تكيه كاه يل

$f r\left(\frac{g y_{t}}{V^{r}}, \frac{d_{\omega_{0}}}{y_{t}}, \frac{\rho_{s}}{\rho_{w}}\right)$

$\mathrm{fr}\left(\mathrm{Fr}, \frac{\mathrm{d}_{\Delta_{0}}}{\mathrm{y}_{\mathrm{t}}}, \mathrm{G}_{\mathrm{s}}\right)$

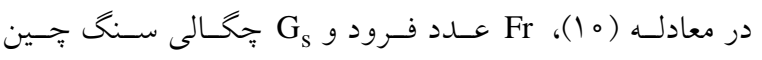

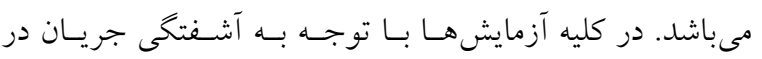

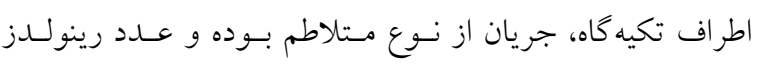
حذف گرديد.

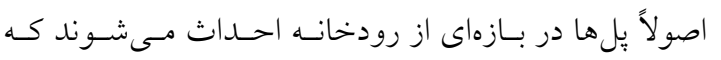

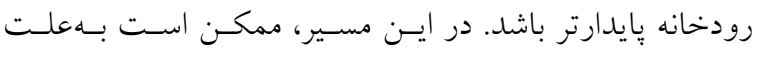

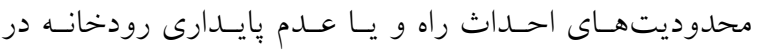

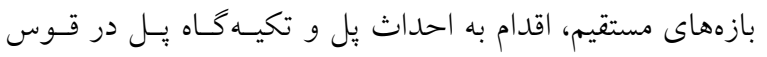

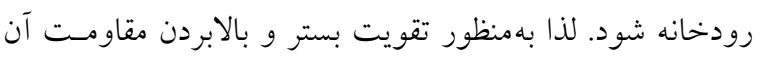

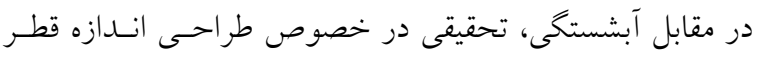

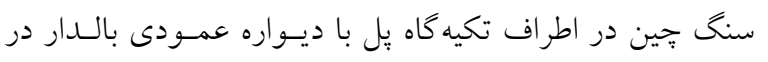

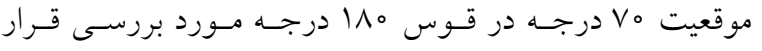

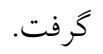

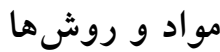

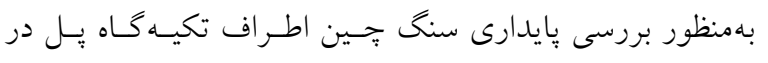

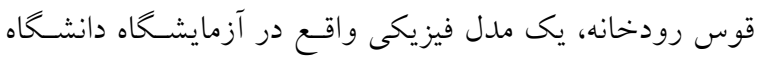

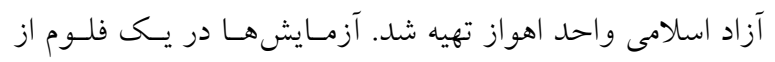

مىدهند و به انتقال ذرات در اطراف تكيه كاه يايه به سمت پيايين

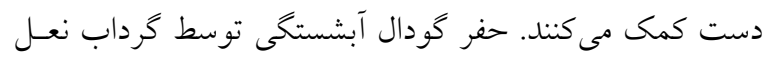

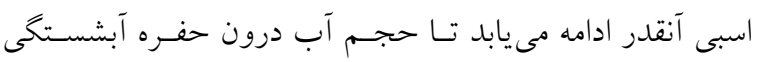

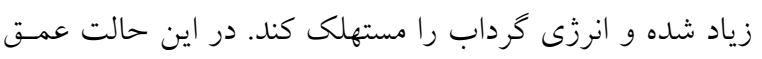

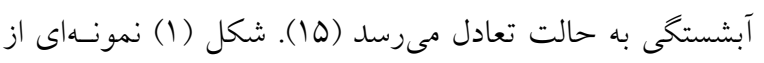

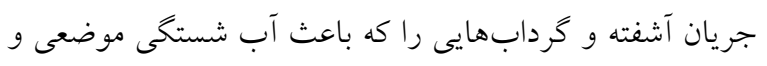
حفره مى گردند را نشان مى دهد. آناليز ابعادى با درنظر كرفتن جريان دائمى و ثابت بودن خصوصسيات سـيال

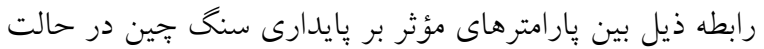
تعادل برقرار است:

f) $\left(\mathrm{R}, \mathrm{B}, \theta, \mathrm{V}, \mathrm{y}_{\mathrm{t}}, \mathrm{g}, \rho_{\mathrm{w}}, \mathrm{S}_{\circ}, \mathrm{d}_{\diamond_{\circ}}, \rho_{\mathrm{s}}\right)=$ 。

در معادله R (V) شعاع مركزى قوس، B عرض مجرا، $\theta$ زاويه

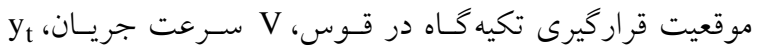

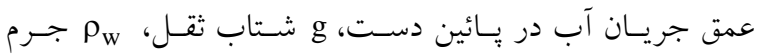

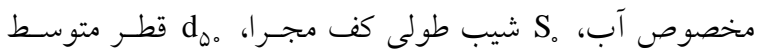

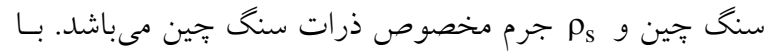
صرفنظر كردن از يارامترهاى ثابت در معادله (V)، معادلـه زيـر

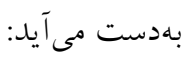

$\mathrm{f})\left(\mathrm{V}, \mathrm{y}_{\mathrm{t}}, \mathrm{g}, \rho_{\mathrm{w}}, \mathrm{d}_{\mathrm{o}_{0}}, \rho_{\mathrm{s}}\right)=。$

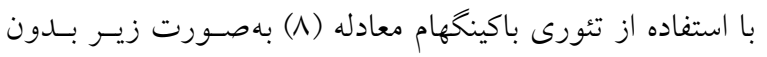

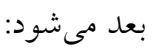




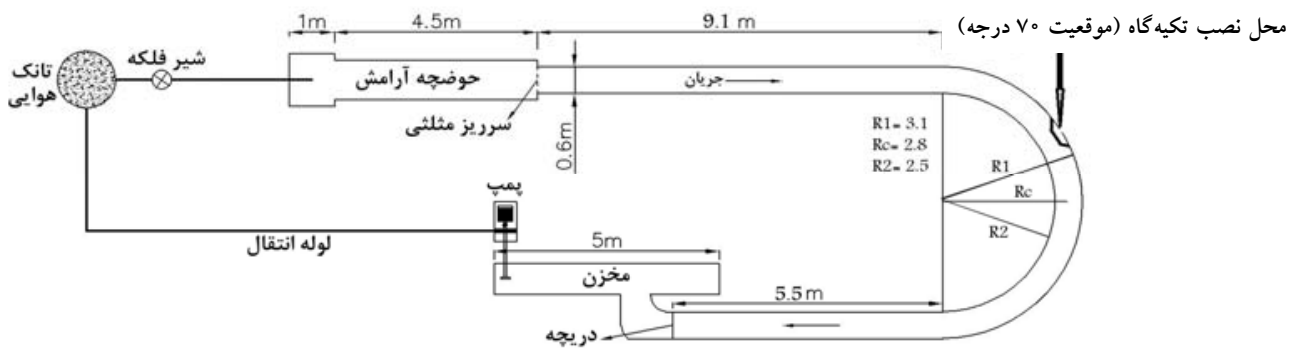

شكل r. بـان كانال قوسى شكل

جدول ا. مشخصات سنى جين در اطر اف تكيه كاه

\begin{tabular}{|c|c|}
\hline اندازه متوسط سنگ جين (mm) & جخالى سنگ جين \\
\hline 19/1، IT/V ، Q/DT، TIVG & $1 / \mathrm{V}$ \\
\hline 19/1، 1T/V، 9/0T & $T / 1$ \\
\hline$I T / V$ & T/MT \\
\hline
\end{tabular}

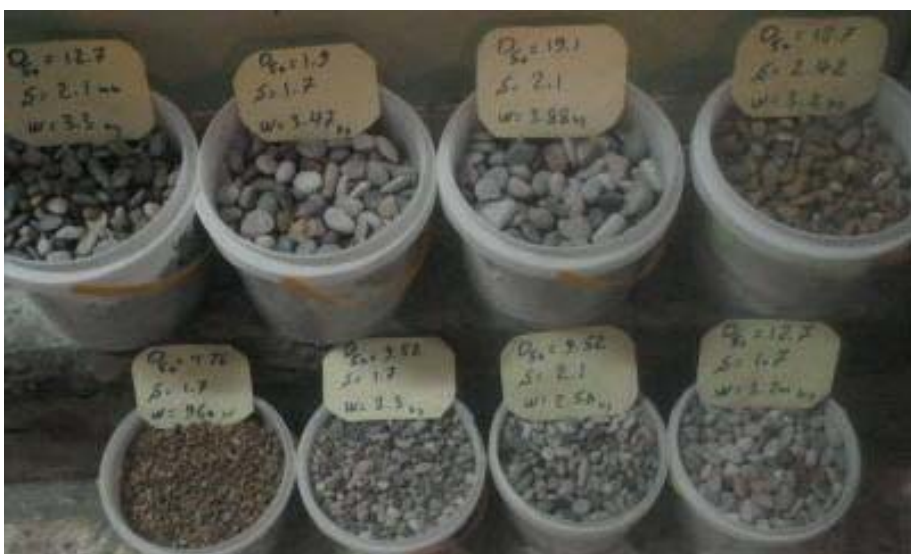

شكل r. نمايى از سنگ جينهاى به كار رفته در تحقيق

نبايد از ه ا درصد عرض كانال بيشتر باشد (^). لذا تكيه كـاه بـا

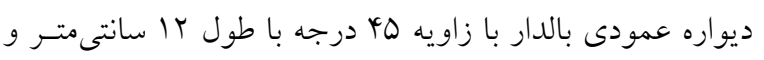

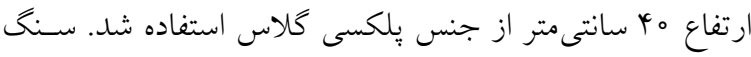

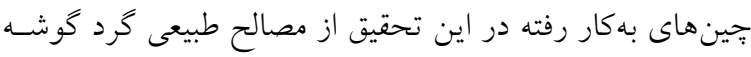

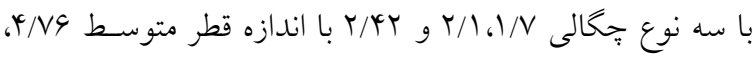

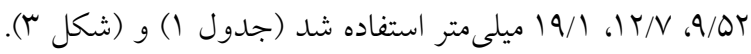
به توصيه راودكيوى و اتما براى جلو كيرى از تشكيل رييـل

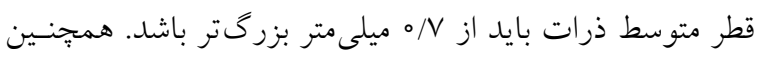

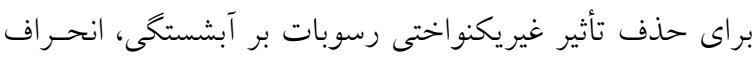

جنس بلاكسى كَلاس قوسى شكل با زاويه مركزى 0111 درجسه،

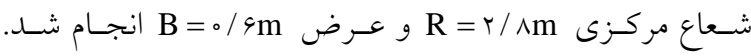
انحنساى نسـبى قـوس R/B = مسوده كـهـ قـوس را در رده

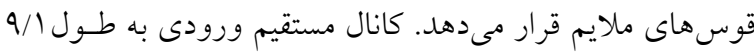

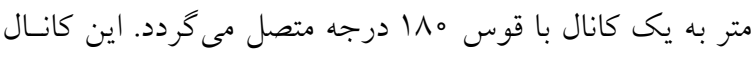

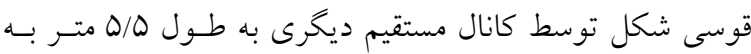

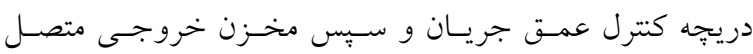
مىشود (شكل r). طبق توصيههاى تجيو و ملويل تنخ شدگى در عرض كانـال 


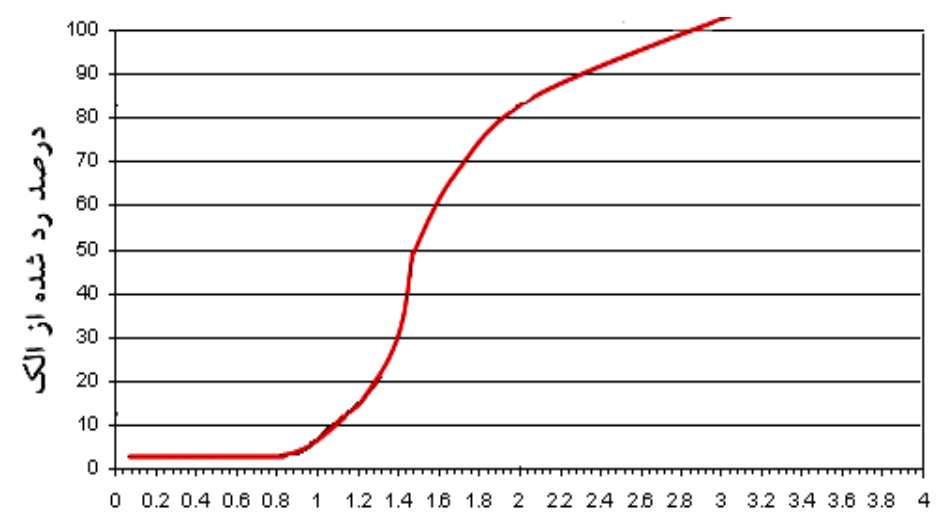

تطر ذرات (mm)

شكل †. منحنى دانهبندى رسوبات بستر در آزمايش

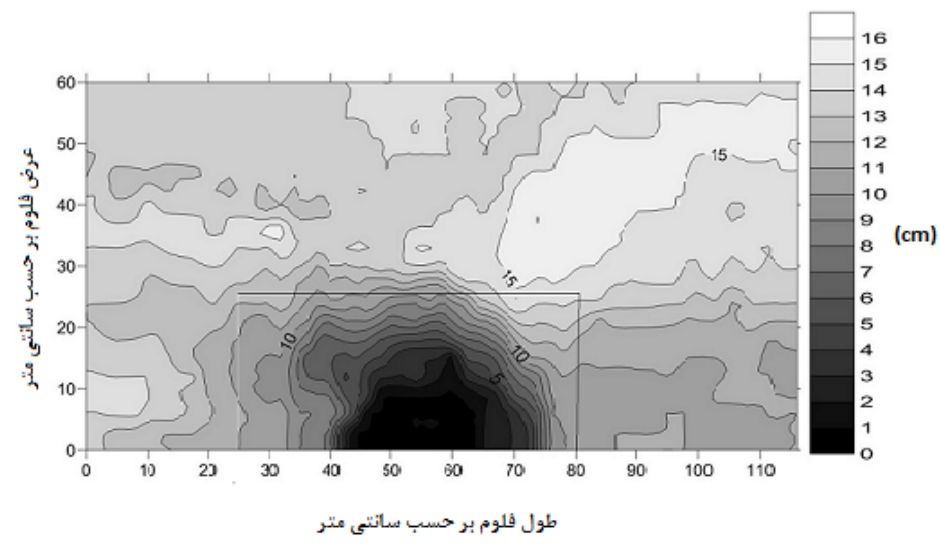

شكل ه. تويو گرافى آبشستخى در اطراف تكيه كاه و تعيين مساحت سنگ جين

ساعت برروى تكيه كاه يل بلدون سنگ جين در يكى لايه از ماسه به ضخامت تقريبى 10 سانتى متر با دبى حداكثر مب ليتر بر ثانيسه

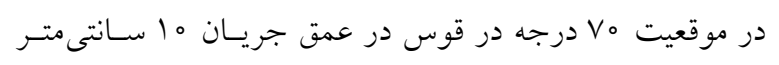

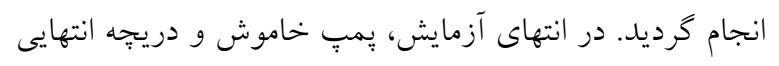

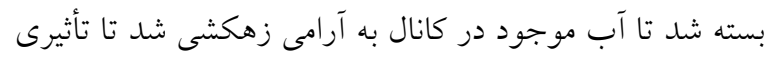

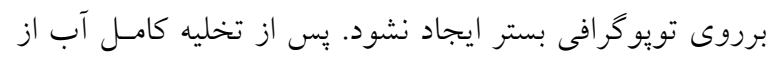

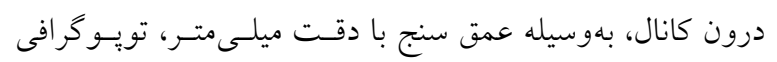
بستر توسط دستخاه عمق سنج با دقت بالا در اطـراف تكيـهــاه

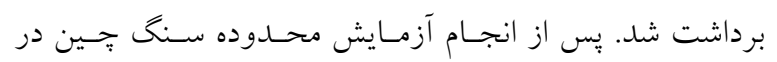

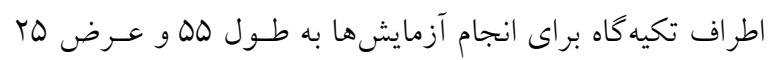
سانتىمتر بهدست آمد (شكل ه).

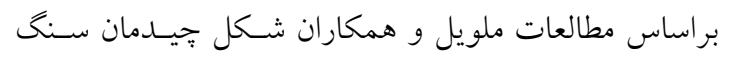

معيار ذرات بايد كمتر از س/1/ باشد († (1). با توجه به ايسن مـوارد

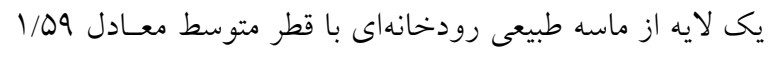

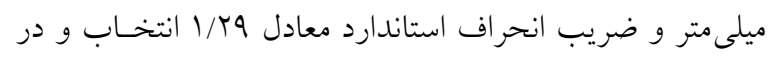

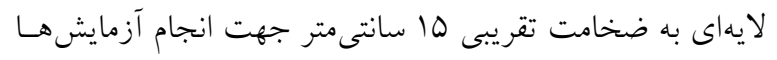
مورد استفاده قرار كرفت (شكل لأل).

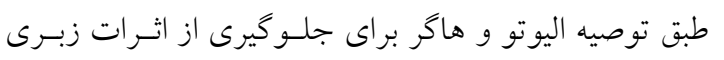

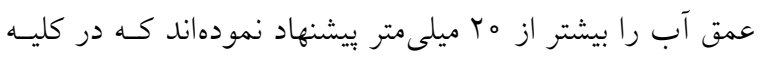

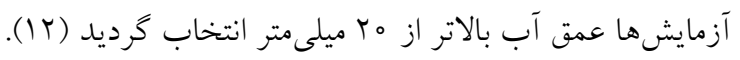
براى تعيين مساحت سنگ جين در اطراف تكيه كاه، آزمايش

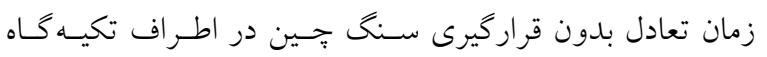

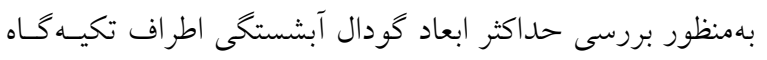

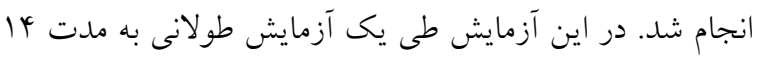



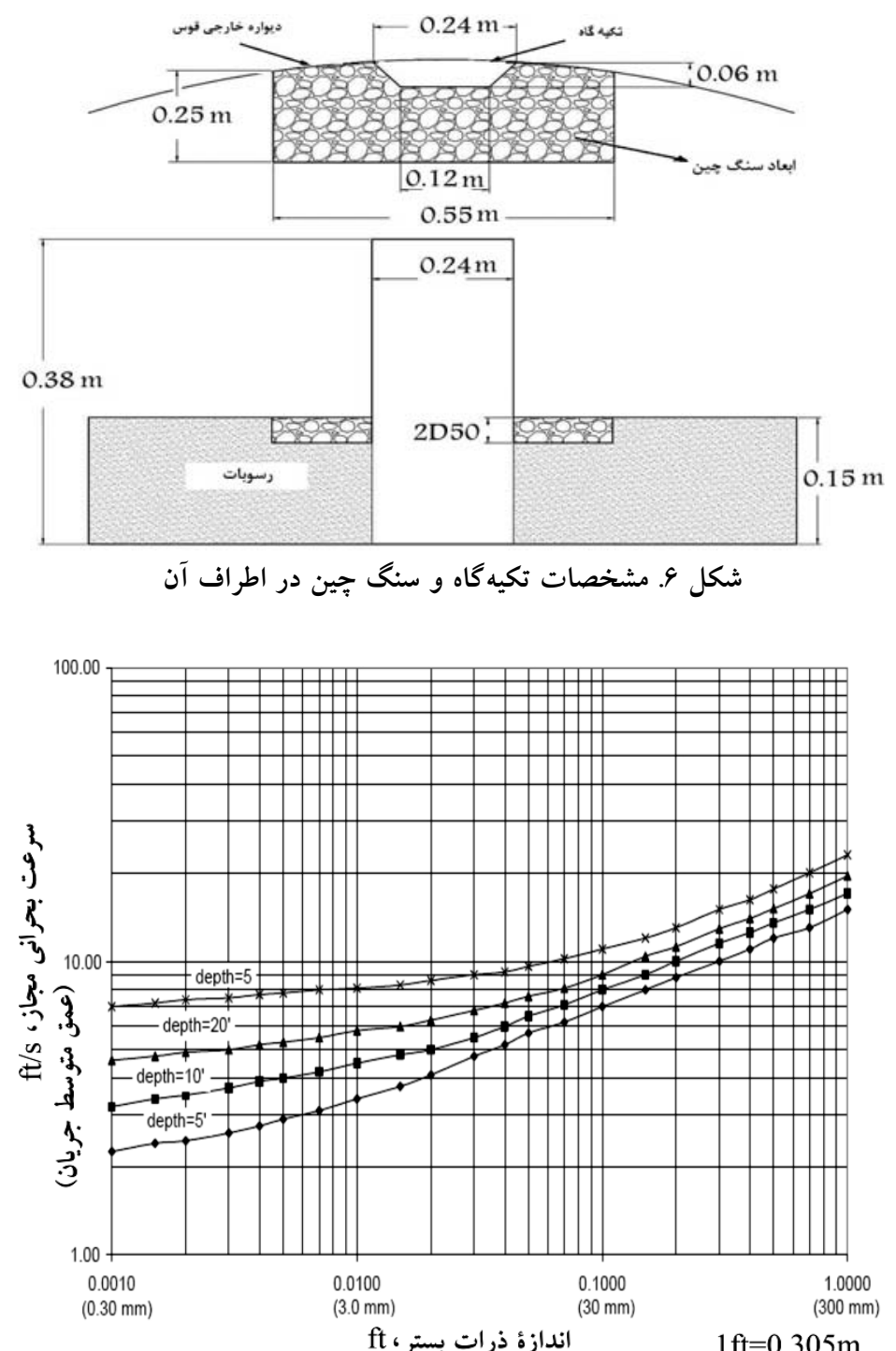

شكل V. منحنىهاى محاسبه سرعت بحرانى به توصيه نيل، (19Vr)

بهمنظور آغاز حركت مصالح بسـتر مسىباشـند. ايسن منحنسىهـا براساس عمق جريان، سـرعت جريـان و انــازه مصـالح بسـتر ترسيم شدهاند. در حقيقت منحنىهاى نيل (19VT) با بهكار بردن

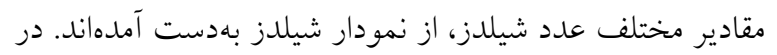
كليه آزمايشها نسبت سرعت برشى به سـرعت برشسى بحرانى مهر

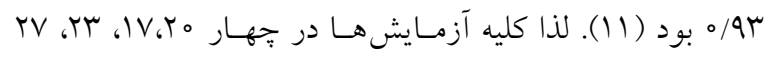
ليتر بر ثانيه انجام شد. دبى مورد نياز توسـط سـرريز مثلثـى درجه در ابتداى ورودى فلوم اندازه كيرى شد. در ابتداى هر آزمايش با استفاده از ارابه متحرك، بستر كانال
جين در اطراف تكيه گاه بهصورت مستطيلى و هم تـراز مصـالح بستر درنظر كرفته شد (0). همجٍنين با توجـه بـه معيـار ارائسه

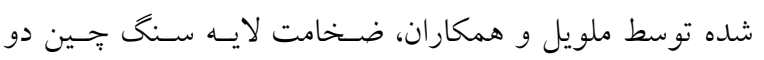
برابر قطر متوسط سنخ جين انتخاب شد ( إ) (شكل 9). با توجه به اينكسه آبشسـتحى موضـعى در شـرايط آب زلال انجام شد، لذا بهمنظور جلو گيرى از فرسايش و انتقال رسـوبات در بالا دست تكيهگ تـاه، سـرعت متوسـط جريـان بايـــ كمتـر از

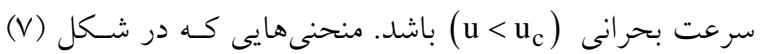
نشـان داده شـدانــد مشـخص كنــــه سـرعت بحرانسى جريـان 
نشر يه علوم آب و خاك (علوم و فنون كشاورزى و منابع طبيعى) / سال بيست و يك / شماره جهار / زمستان وهـ1

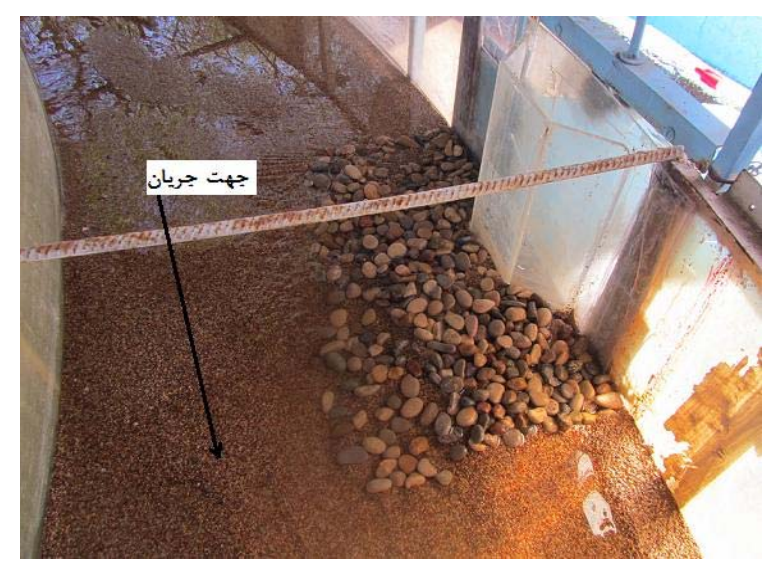

شكل 9. آستانه شكست سنگ جֶين

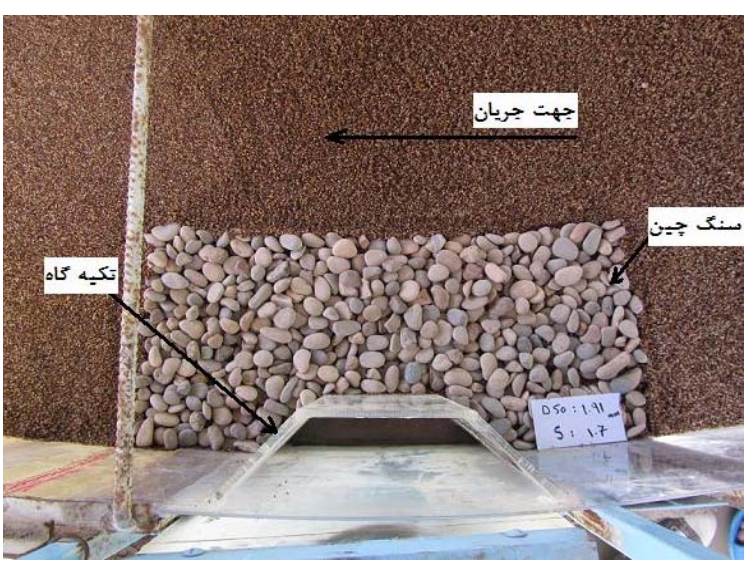

شكل ^م تكيه گاه و سنگ جين اطراف آن قبل از آزمايش

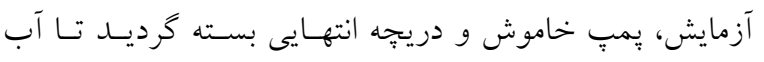

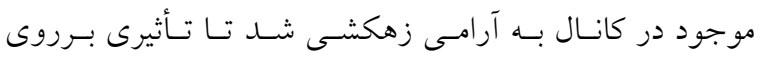

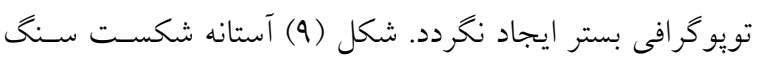
جين در انتهاى آزمايش نشان داده شده است.

\section{بحث و نتايج}

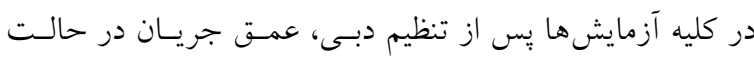

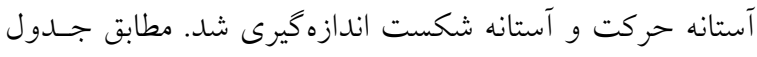

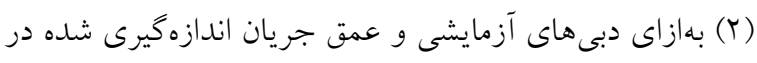

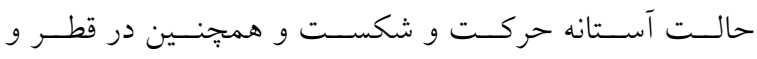

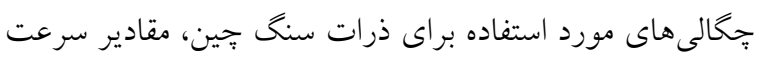
متوسط جريان و عدد فرود در دو حالت آستانه حركت و آستانه شكست محاسبه شد.

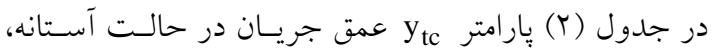

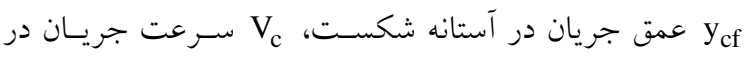

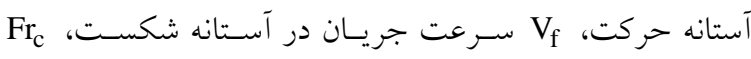

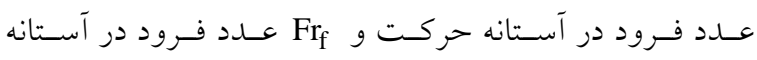
شكست مىباشند.

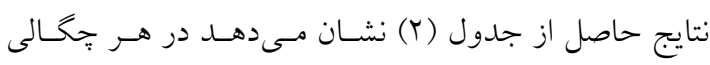

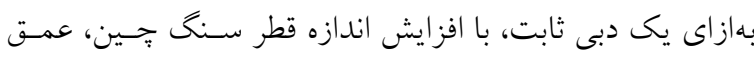

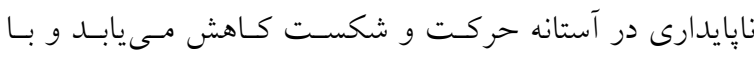

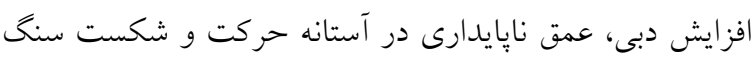

تحت شيب ثابت مسطح گرديد. سيس سنگ جين مورد نظر بـا

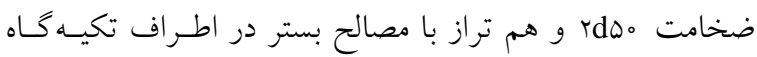

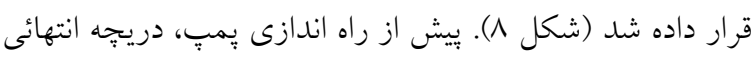

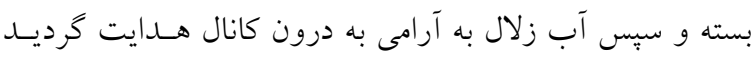

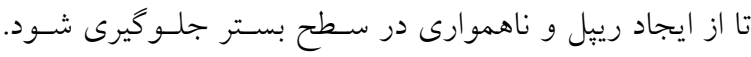

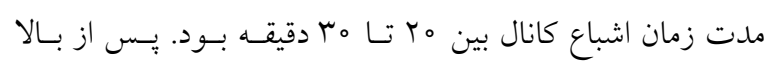

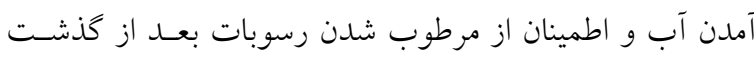

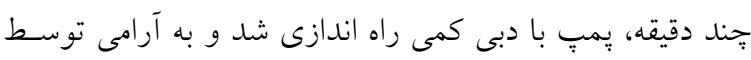

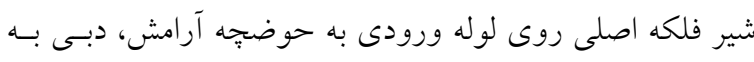

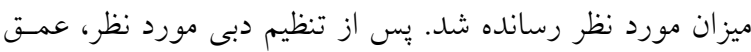

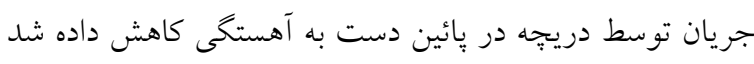

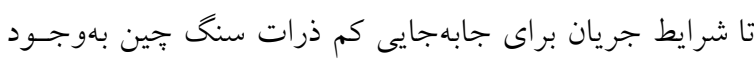

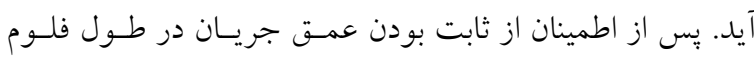

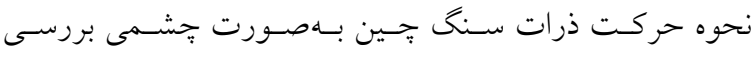

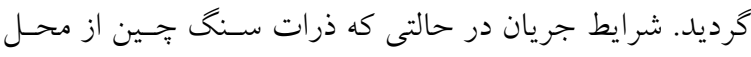

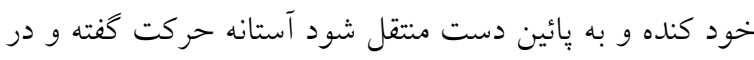

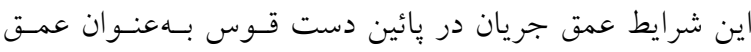

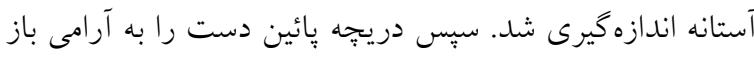

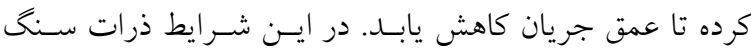

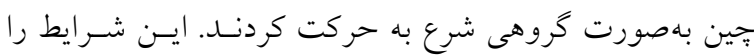

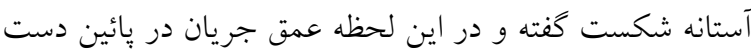

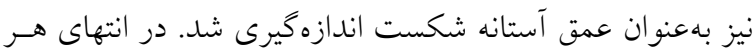


بررسى اندازه قطر سنگ جين در اطراف تكيه گاه يٍ در قوس •\ا درجه رودخانه

\begin{tabular}{|c|c|c|c|c|c|c|c|c|}
\hline \multicolumn{9}{|c|}{ جدول r. نتايج حاصل از آزمايش آستانه حركت و آستانه شكست سنگ جين } \\
\hline Gs & $\mathrm{Q}\left(\mathrm{m}^{r} / \mathrm{s}\right)$ & $\mathrm{D} \bowtie \cdot(\mathrm{mm})$ & $\mathrm{y}_{\mathrm{tc}}(\mathrm{m})$ & $\mathrm{V}_{\mathrm{c}}(\mathrm{m} / \mathrm{s})$ & $\mathrm{Fr}_{\mathrm{C}}$ & $\mathrm{y}_{\mathrm{tf}}(\mathrm{m})$ & $\mathrm{V}_{\mathrm{f}}(\mathrm{m} / \mathrm{s})$ & $\mathrm{Fr}_{\mathrm{f}}$ \\
\hline $1 / V$ & $0 / 01 \mathrm{~V}$ & Y /VG &.$/ 1190$ & $O / Y Y$ & $0 / Y \mu$ & $\circ / \circ 9 V$ & $0 / 7 q$ & $\circ / \mu$ \\
\hline $1 / V$ & $0 / 01 \mathrm{~V}$ & $Q / D T$ &.$/ 094$ & $\circ / \mu$ & $0 / \mu 1$ & $0 / 0 \wedge 1$ & ه & $0 / \mu q$ \\
\hline $1 / V$ & $0 / 01 \mathrm{~V}$ & $I T / V$ & $\circ / \circ \wedge \Delta$ & سא/ס & $\circ / T V$ & $\circ / 0 V T$ & $0 / \pi q$ & $0 / 49$ \\
\hline $1 / V$ & $.01 \mathrm{~V}$ & $19 / 1$ & $0 / 0 V Y$ & $0 / 4 q$ & $0 / \& V$ & $0 \% 91$ & OKY & .01 \\
\hline $1 / V$ & $0 \%$ & $Y / V G$ & $0 /|r|$ & $0 / Y \Lambda$ & $0 / T \Delta$ &.$/ 111$ & $0 / \mu$ & $0 / 7 q$ \\
\hline $1 / V$ & $\% / O Y$ & $9 / 0 T$ & $0 / 091$ & $0 / M Y$ & $\circ / \Gamma \Delta$ & $\circ / 0 \wedge 9$ & $\circ / \mu V$ & $\circ / 4$ \\
\hline $1 / V$ & $0 / 04$ & $I T / V$ & $\circ / \circ \wedge$ & $0 / \mu$ & $0 / 41$ & $\circ / 0 \vee q$ & OMY & $\circ / 4 \wedge$ \\
\hline $1 / V$ & $\% \% r$ & $19 / 1$ & $0 / 0 V 9$ & $0 / 4 k$ & $0 / 01$ & $\circ / 0 V T$ & $0 / 49$ & $\circ / \Delta \Delta$ \\
\hline $1 / V$ & & $\varphi / v q$ & O/KA & $\circ / \mu$ & $0 / T V$ & $0 / 11 \mathrm{~V}$ & سח/ם & $0 / \mu$ \\
\hline $1 / V$ & ס/Or & $Q / 0 r$ & $\circ / 1 \circ \Delta$ & $0 / N V$ & $0 / 44$ & $0 / 090$ & $0 / 4$ & O/AY \\
\hline $1 / V$ & MTH & $I T / V$ &.$/ 0940$ & $0 / 41$ & o/Ar & ०/०ᄉkr & $0 / 40$ & $\circ / 0$ \\
\hline $1 / V$ & سTH & $19 / 1$ & \%०Ar & $0 / 4 V$ & - /Or & $\circ / \circ V V$ & $0 / 0$ & $\circ / Q V$ \\
\hline $1 / V$ & ०/OTV & I/VG & Dهt/M & سד/ם & $0 / Y q$ & OMYY & G & س \\
\hline $1 / V$ & $0 / 0 Y V$ & $9 / 0 T$ & $0 / 11 Y$ & $0 / 4$ & $\circ / \mu$ & $0 / 101$ & $0 / 40$ & $0 / 40$ \\
\hline $1 / V$ & $0 / 0 T V$ & $I T / V$ & $\circ / 1 \circ 4$ & $0 / 4 r$ & $0 / 4 r$ & .094 & $0 / 49$ & - Q QY \\
\hline $1 / V$ & O/OTV & $19 / 1$ & $0 / 09$ & $\circ / 0$ & -/Or & $\circ / 0 \wedge 9$ & - $/ \Delta T$ & $\circ / \Delta V$ \\
\hline$r / l$ & $0 / 01 \mathrm{~V}$ & $Q / D T$ &.$/ 094$ & $0 / \mu$ & O/TY & $0 / 0 \vee q$ & G/4 & $0 / 41$ \\
\hline$r / I$ & $.01 \mathrm{~V}$ & $I T / V$ & $\circ / \circ \wedge 1$ & $0 / \pi \Delta$ & $0 / 4 q$ & $\circ / \circ \mathrm{V}$ & $0 / 4$ & $0 / 49$ \\
\hline$r / l$ & $0 / 01 \mathrm{~V}$ & $19 / 1$ & $\circ / 0 V$ & $0 / 4$ & $0 / 4 q$ & .1090 & $0 / 4 y$ & $\circ / 00$ \\
\hline$T / I$ & $0 / 0 Y$ & $Q / D T$ & $0 / 094$ & ס & $\circ / \mu V$ & $\circ / \circ \wedge \Delta$ & $0 / 4 q$ & D \\
\hline$r / I$ & O०Y & $I T / V$ & \%०ᄉr & $0 / 41$ & $\circ / 4 Q$ & $\circ / \circ \vee \wedge$ & $0 / 4 \mu$ & $0 / 49$ \\
\hline$r / I$ & O०Y & $19 / 1$ & $0 / 0 V Y$ & $0 / 49$ & $\circ / \Delta \Delta$ & $\circ / \circ \mathrm{V}$ & $0 / 4 \wedge$ & $\circ / \Delta V$ \\
\hline$r / I$ & & $Q / D T$ & $0 / 101$ & $0 / \mu$ & $\circ / \mu \wedge$ & $0 / 091$ & O/AT & $\circ / 40$ \\
\hline$r / I$ & & $I T / V$ & $0 / 09$ & Tr/א & $0 / 40$ & $\circ / 0 \wedge r$ & $0 / 4 \wedge$ & - $/ Q T$ \\
\hline$r / I$ & & $19 / 1$ & $\circ / 0 \mathrm{VV}$ & $0 / 0$ & $\circ / \Delta V$ & $\circ / \circ Q$ &.$/ 01$ & $0 / 9$ \\
\hline$r / l$ & ०/OTV & $Q / D T$ & $0 / 109$ & $0 / 41$ & $\circ / 4$ & $0 / 099$ & $0 / 4 \Delta$ & $0 / 49$ \\
\hline$r / l$ & ०/०TV & $I T / V$ & $0 / 091$ & $0 / 49$ & $\circ / \notin V$ & $0 / 0 \wedge 9$ &.$/ 01$ & $\circ / D t$ \\
\hline$r / l$ & $0 / 0 Y V$ & $19 / 1$ & $0 / 0 \wedge r$ &.$/ Q F$ & $0 / 09$ & $\circ / \circ \wedge$ &.$/ 09$ & $0 / 94$ \\
\hline T/MY & $0 / 01 \mathrm{~V}$ & $I Y / V$ & $\circ / 0 V 1$ & $0 / 4$ & $0 / \uparrow \wedge$ & 01049 & $0 /$ M & - \\
\hline T/KT & O०Y & $I T / V$ & \% OVVD & D & $0 / 49$ & $0 / 099$ & $0 / 4 \wedge$ &.$/ 09$ \\
\hline T/YY & תוT & $I T / V$ & ०/ノTQ & $0 / 49$ & o/Or & $\circ / 0 V^{f}$ & - /Dr & $0 / 91$ \\
\hline T/KY & $0 / 0 Y V$ & $I T / V$ & $0 / 0 \wedge 9$ &.$/ 01$ & $\circ / \Delta Y$ & $\circ / \circ \wedge 10$ & $\circ / \Delta \Delta$ & $0 / 94$ \\
\hline
\end{tabular}

(D 0 ر جهار دبسى IV/yt ) ج جالى 1/V و T/1 در دو حالت آستانه حركت و آستانه شكست

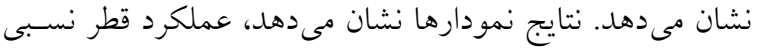
سنخدانهها در دو حالت آستانه حركت و شكست به عدد فـرود جريان بستخى دارد و در شرايط زير بحرانى در كليه دبىهـا، بـا افزايش عدد فرود، قطر نسبى سنحـانههـا در دو حالـت آسـتانه

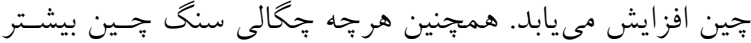
شود، آستانه حركت و شكست سنگ جين در اعماق يُائينتسرى رخ مىدهد. بررسى تأثير عدد فرود بر قطر نسبى سنگدانه شكل (10) و (11) تـأثير عـدد فـرود در قطـر نسـبى سـنحدانه 
آستانه حركت

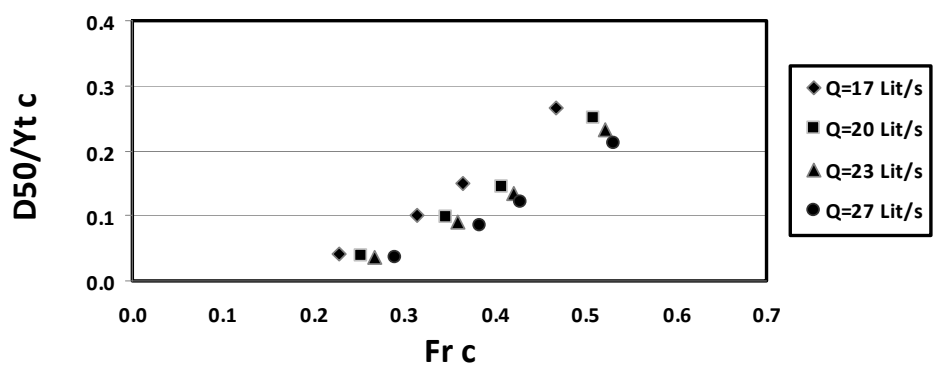

آستانه شكست

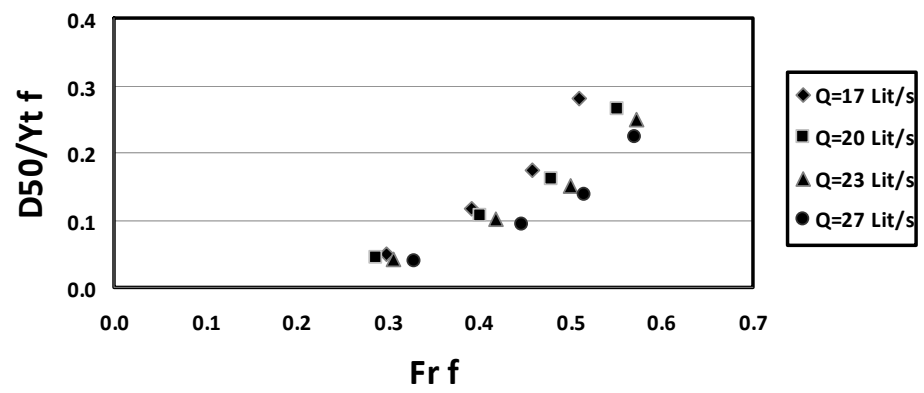

شكل ه ا. تأثير عدد فرود بر قطر نسبى سنكدانها در حالت آستانه حركت و شكست در جخالى 1/V

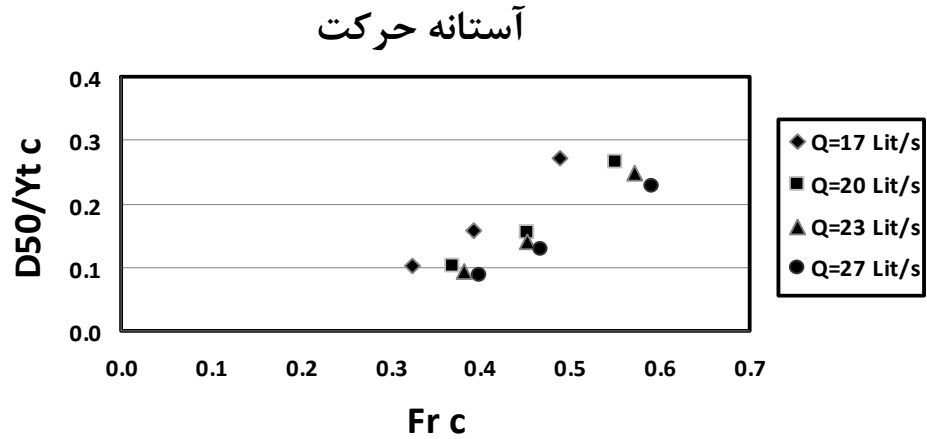

آستانه شكست

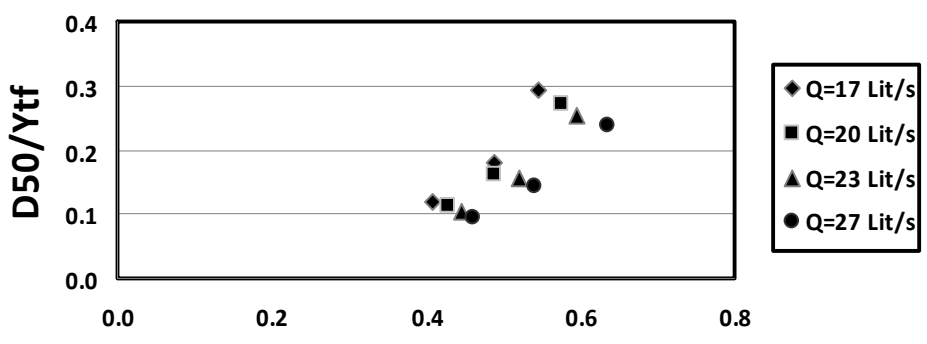

Frf

شكل 11. تأثير عدد فرود بر قطر نسبى سنكدانهها در حالت آستانه حركت و شكست در جحالى 


\begin{tabular}{|c|c|c|}
\hline \multicolumn{3}{|c|}{ جدول r. مقايسه نتايج تحقيق حاضر با نتايج محققين } \\
\hline تحقيق ارائه شده & RMSE & RMSE \\
\hline تحقيق حاضر & $\%$ \%ry & $\%$ \% \\
\hline منصورى - شفاعى بجستان ( 1 (1 ) & $\circ \% \circ \wedge$ & $0 / 014$ \\
\hline سازمان حمل و نقل و ترافيك نيوزلند و استر اليا(1994) &.$/ 01 V$ &.$/ 141$ \\
\hline سايمون و لويس(19V|) & . & 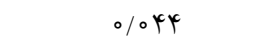 \\
\hline يِاكان- ارتيز (1991)(تكيه كاه با ديواره نوك دايره اى) & .044 &.$/ 014$ \\
\hline 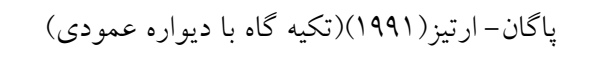 & $\circ / \circ \vee^{\circ}$ & 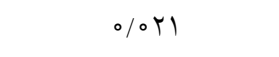 \\
\hline
\end{tabular}

\section{نتيجه گيرى نهائى}

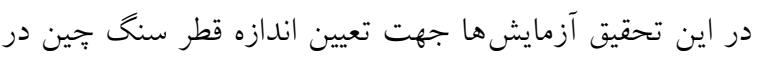

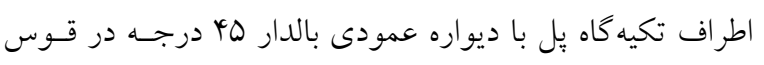

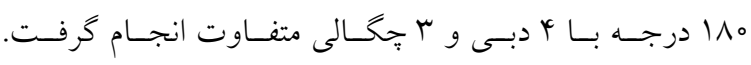

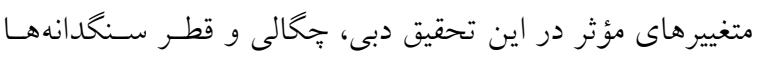

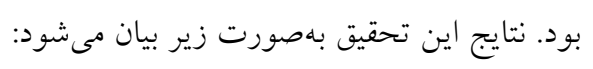

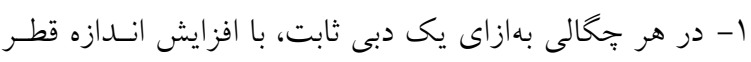

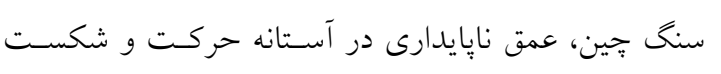

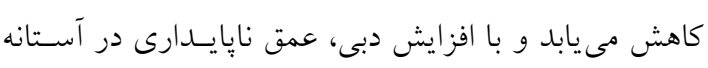

$$
\text { حركت و شكست سنخ جين افز ايش مى يابد. }
$$

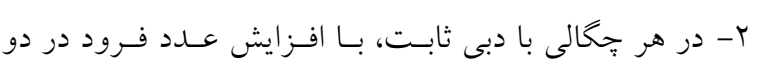

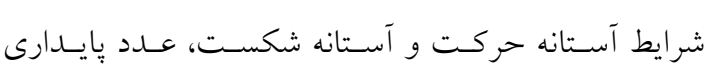

$$
\text { كاهش مىيابد. }
$$

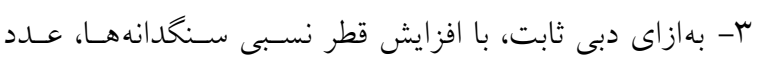

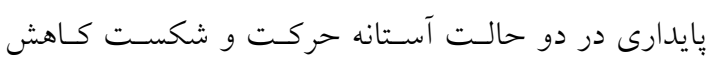

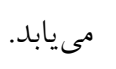

ץ- در كليه دبىها، با افزايش عدد فرود، قطر نسبى سنخدانههـا

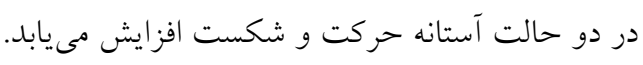

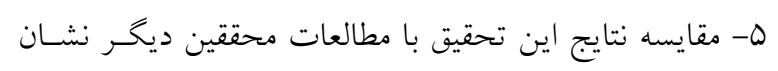

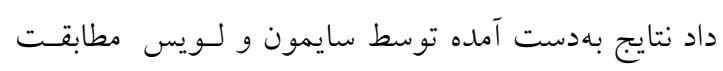

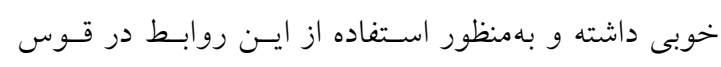

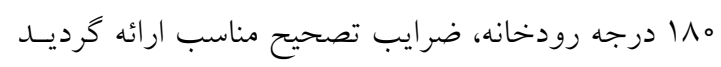

حركت و شكست افزايش مى يابد. بهعبارت ديخر در دبى ثابت،

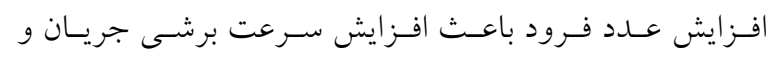

$$
\text { نايايدارى سنش جين ها مى شيود. }
$$

بهمنظور تخمين اندازه قطر سنخدانهها در اطراف تكيه كاه يـلـ

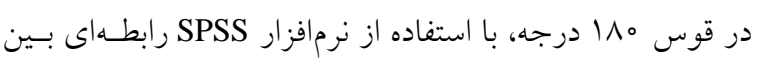

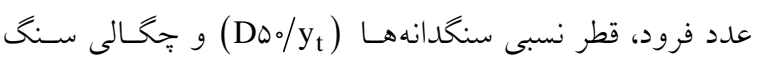

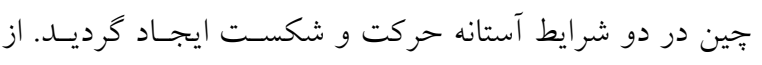

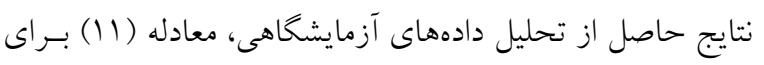

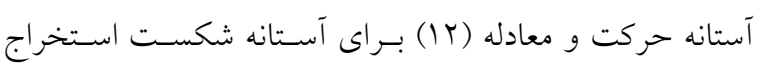
كرديد. مقدار ضريب همبستخى اين دو رابطه هم/ه مى مباشد:

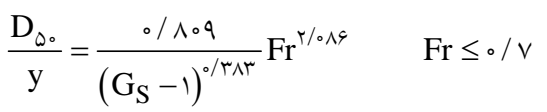

$\frac{D_{\omega_{0}}}{\mathrm{y}}=\frac{0 / \mathrm{VAr}}{\left(\mathrm{G}_{\mathrm{S}}-1\right)^{0 / \mu r \varphi}} \mathrm{Fr}^{\left.\mathrm{r} /{ }^{\prime}\right)} \quad \mathrm{Fr} \leq \circ / \mathrm{V}$

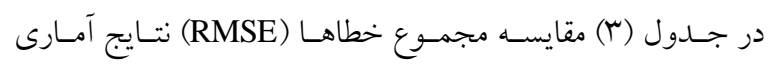
تحقيق حاضر با نتايج محققين در شرايط آستانه حركت و شكست آنايس

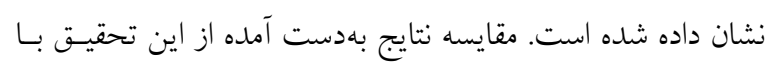

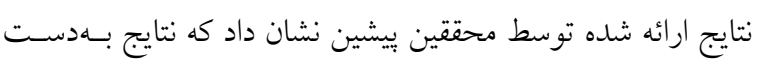

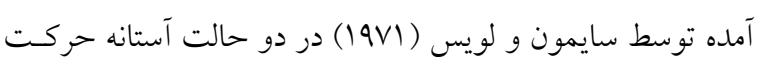
شكست بهدليل درصد خطاى كمتر، مطابقت بسيار خوبى با نتـايج

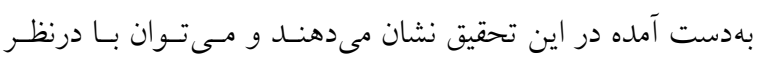

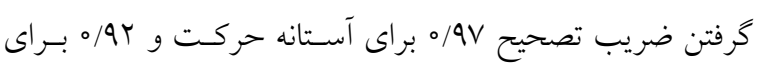

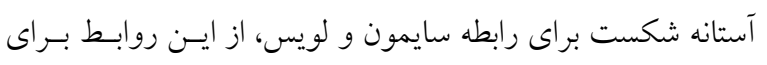

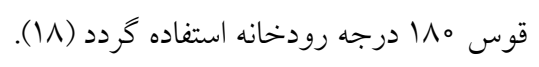




$$
\begin{aligned}
& \text { منابع مورد استفاده } \\
& \text { ا. صانعى، م. هیז1، بررسى آزمايشگاهى اثر درصد انسداد در آبشستكى موضعى آب شكن ها، هفتمين سمينار بين المللى مهندسى }
\end{aligned}
$$

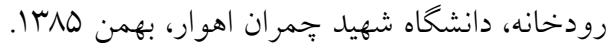

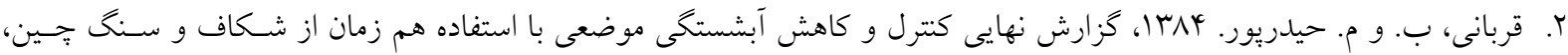

$$
\begin{aligned}
& \text { دانشخاه شهركرد و صنعتى اصفهان، rابـ }
\end{aligned}
$$

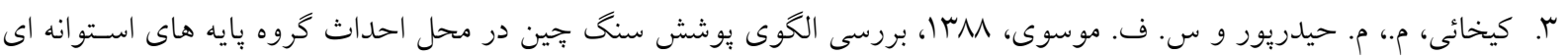

$$
\begin{aligned}
& \text { در يل ها، مجله علوم فنون كشاورزى و منابع طبيعى با( }
\end{aligned}
$$

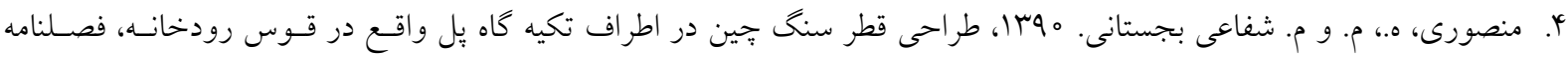

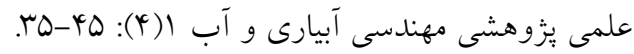

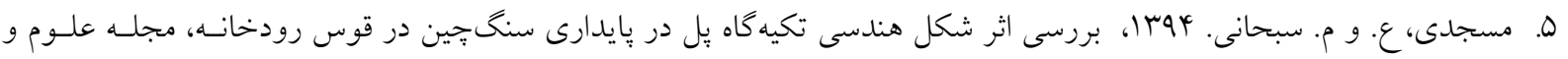

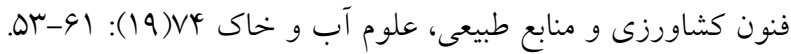

6. Austroads, 1994. Waterway design, A guide to the hydraulic design of bridges, culverts and floodways, Sydney, Australia.

7. Breusers, H. N. C., G. Nicollet, H. W. Shen. 1977. Local scour around cylindrical piers. J. of Hydraulic Res. IAHR. 15(3): 211-252.

8. Chiew, Y. M. and B. W. Melville. 1987. Local scour around bridge piers. J. of Hydraulic. Research, 25(1):15-26.

9. Melville, B.W. and S.E. Coleman. 2000. Bridge Scour. Water Resources Publications. Highlands Ranch. Colo.

10. Melville, B. W., S. Van Ballegooy, S. E. Coleman and B. Barkdoll. 2007. Riprap size selection at wing-wall abutment. ASCE. J. Hydraulic. Eng. 133(11): 1265-1269.

11. Neil, C. R. 1973. Guide to Bridge Hydraulics. Road and Transportation Association of Canada, University of Toronto, Canada.

12. Oliveto, G.and W. H. Hager. 2002. Temporal evolution of clear-water pier and abutment scour. J. of Hydraulic. Eng. ASCE. 128(9): 811-820.

13. Pagan-Ortiz, J. E. 1991. Stability of rock riprap for protection at the toe of abutments located at the flood plain Rep. No. FHWA-RD-91-057. Feederal Highway Administration U.S. Dept. of Transportation Washington D.C.

14. Raudkivi, A. J. and R. Ettema. 1983. Clear-water scour at cylindrical piers. J. of Hydrulic Eng. ASCE. 109(3): 338350.

15. Raudkivi, A. J. 1998. Loose boundary hydraulics. 4th Edition. Rotterdam ; Brookfield, VT : Balkema. 496 p.

16. Richardson, E.V. and S. R. Davis. 1995. Evaluating scour at bridges. Hydraulic Engineering Circular, No. 18, $3^{\text {rd }}$ Ed. Rep. No. FHWA-IP-90-017. Office of Techology Applications. HTA-22. Feederal Highway Administration U.S. Dept. of Transportation Washington D.C.

17. Simarro, G., Ch. Chreties and L. Teixeria. 2011. Riprap sizing for pile group. J. of Hydraulic Eng., doi:10.1061/(ASCE)HY.1943.1943-7900.0000458.

18. Simons, D.B. and G. L. Lewis. 1971. Flood protection at bridge crossings. C.S.U. Civil Engineering Rep. No. CER71-72DBS-GL10. Prepared for the Wyoming State Highway Dept. in Conjunction with the U.S. Dept. of Transportation Washington D.C.

19. Sui, J., H. Afzalimehr, A. Kabiri Samani and M. Maherani. 2010. Clear-water scour around semi-elliptical abutments with armoured beds. Int. J. of Sediment Res. 25(3):233-244.

20. Zarrati, A. R., M. Nazariha and M. B.Mashahir. 2006. Reduction of local scour in the vicinity of bridge pier groups using collars and riprap. ASCE. J. Hydrauicl. Eng. 132(2):154-162. 


\title{
Investigation of Diameter of Riprap around the Bridge Abutment at 180-Degree River Bend
}

\author{
M. Naserian and A. Masjedi ${ }^{*}$
}

(Received: July 08-2013 ; Accepted: April 04-2017)

\begin{abstract}
River bend due to particular pattern, called 'Vortex Flow,' has greater erosion than straight path. Occurrence of scour around bridge abutment on curved paths is one of the main reasons for destruction of bridges. Riprap is one of the methods to control the scouring around the bridge abutment. The purpose of this study was to assess stability of the riprap around the bridge abutment at 180 degree river bend. In order to study stability of riprap around the bridge abutment, experiments were done in a laboratory flume made of Plexiglas under 180 degree bend, $2.8 \mathrm{~m}$ in central radius, $0.6 \mathrm{~m}$ in width and $\mathrm{R} / \mathrm{B}=4.67$. In this research, several experiments were done by placing a bridge abutment with vertical winged wall made of Plexiglas surrounded by a series of riprap. Experiments were done by three different types of riprap with different density 1.7, 2.1 and 2.42, four different diameters 4.76, 9.52, 12.7 and $19.1 \mathrm{~mm}$ and four rates of discharge under pure water condition. In each experiment, flow depth was measured in terms of moving threshold and failure threshold and then the formulas were calculated by using data obtained. The results showed that the relative diameter of riprap increased with increasing Froude number in terms of moving threshold and failure threshold. Finally, the suitable formula to estimate diameter of riprap around the bridge abutment at 180 degree bend were presented in terms of moving threshold and failure threshold.
\end{abstract}

Keywords: 180 degree bend, Bridge abutment, Riprap, Secondary flow.

1. Dept. of Water Eng., Faculty of Agric., Islamic Azad Univ., Ahvaz Branch, Ahvaz, Iran.

*: Corresponding Author, Email: drmasjedi.2007@yahoo.com 